\title{
Transformação da percepção da menstruação entre gerações
}

\author{
Maria Luísa Eleutério Mundim \\ Milena Polizelli Leite de Souza \\ Vitor Castalões Gama
}

Resumo: $O$ presente artigo busca refletir sobre o tabu acerca da menstruação. Avaliamos como se dá a transformação da percepção e da prática do ciclo menstrual entre gerações, em paralelo com as ideias de profano de Robert Hertz. Por meio de uma netnografia, entramos em contato com mulheres para entender sua historicidade e experiência com o mênstruo. Percebemos que, mesmo diante de uma evolução, persistem, ainda, alguns estigmas.

Palavras-chave: Menstruação. Tabu. Gerações. Netnografia. Robert

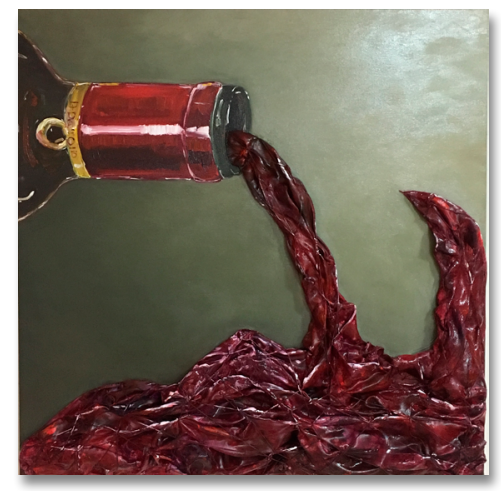
Hertz.

\section{Maria Luísa Eleutério Mundim}

Graduanda no curso de Ciências Sociais da Universidade de São Paulo (USP).

E-mail: malu.eleuterio@usp.br

$\overline{\text { Milena Polizelli Leite de Souza }}$

Graduanda no curso de Ciências Sociais da Universidade de São Paulo (USP).

E-mail: milenapolizelli@usp.br

\section{Vitor Castalões Gama}

Doutorando na Universidade de Brasília, Mestre pela mesma instituição e vinculado à Secretaria de Estado de Educação do Distrito Federal. Tem pesquisado sobre a literatura fantástica, psicologia e outras artes.

E-mail: vitorcasteloesgama@hotmail.com

\section{Transformation of the perception of menstruation between generations}

\begin{abstract}
The present article seeks to reflect on the taboo of menstruation. We evaluate the transformation of the perception and practice of the menstrual cycle between generations, in parallel with the ideas of the profane by Robert Hertz. Through a netnography, we contacted women to understand their history and experience with menstruation. We realized that, even in the face of progress, some stigmas still persist.
\end{abstract}

Keywords: Menstruation. Taboo. Generations. Netnography. Robert Hertz.

RECEBIDO: $28 / 06 / 2020$

APROVADO: 09/12/2020 


\section{Introdução}

A menstruação tem sido estudada como ponto chave da função reprodutiva da mulher há diversos anos, especialmente por profissionais da saúde, os quais expuseram e avançaram no conhecimento sobre uma extensa parte do funcionamento fisiológico dos órgãos sexuais e das consequências hormonais dos distintos momentos do ciclo menstrual. Contudo, esses estudos possuem uma perspectiva majoritariamente mecanicista e acabam por reforçar e propugnar um papel da mulher na sociedade como puramente reprodutora. Assim, o tratamento clínico dos sintomas da menstruação muitas vezes segue protocolos alheios às particularidades de cada realidade social, ao histórico menstrual e cultural, às expectativas individuais e sociais e às variadas práticas e tecnologias existentes, gerando uma pressão sobre a padronização do ciclo que perpetua os significados da impureza contagiosa, da fraqueza e do interdito ao redor do tema.

Neste artigo, buscamos refletir sobre o tabu da menstruação a partir de nossa leitura de A preeminência da mão direita: um estudo sobre a polaridade religiosa, de Robert Hertz (1980). Analisamos o teor que essa atividade corporal adquiriu em contextos históricos, sociais e culturais a partir de uma netnografia em que pesquisamos como a interpretação e a prática do ciclo menstrual se transformam com o passar das gerações. Nosso objetivo era observar como mulheres de idades variadas percebem a menstruação e como agem diante dela, se utilizando de múltiplas tecnologias. Foram entrevistadas mulheres cisgênero e de classe média da Zona Norte de São Paulo e do Plano Piloto de Brasília, seguindo roteiro semiestruturado e que as permitiam relatar suas experiências com o mênstruo. Enfocamos no leque de sentimentos, reações, atitudes e conceitos que essas mulheres levam consigo sobre o menstruar. Nossas questões centrais rondavam sobre: a transmissão dos conhecimentos de mãe para filha; a recorrência do assunto em espaços heterogêneos; a perenização de estigmas; e o peso da mídia social para informar as mulheres e romper tabus.

Começamos nossas ponderações apresentando a oposição entre sagado e profano de Hertz (1980), ou entre a sociedade dos homens e a sociedade das mulheres. É nesse panorama que 
instituições sociais, por meio de práticas de mutilação e princípios religiosos, tentam promover o apagamento social das mulheres. Desse modo, a realidade reprodutiva feminina é vista como impura e não natural, tornando-se vítima de represálias e de censuras.

Nossa expectativa é a de que a pluralidade dos corpos seja compreendida e aceita, ao darmos visibilidade a este debate no âmbito acadêmico. Sendo assim, nossa pesquisa se atenta aos fatores individuais da historicidade de cada mulher, ao jeito singular pelo qual vivência e interpreta a menstruação, ao levar em conta antecedentes e experiências particulares, como o estresse, as técnicas corporais, as visões de mundo e a sociedade em que estão inseridas.

Além de outras pesquisas sobre o mênstruo, nos embasamos em Robert Hertz (1980) e nas reflexões sobre as técnicas corporais de Marcel Mauss (2017). Ambos trazem poderosos insights sobre costumes dominantes, suas funções e sua manutenção. Para Mauss (2017, p. 421), as técnicas do corpo são "as maneiras como os homens, de sociedade a sociedade, de uma forma tradicional, sabem servir-se de seu corpo". Dessa forma, práticas passadas através da imitação prestigiosa, ou seja, da repetição de atos de pessoas de autoridade, seriam traduzidas como costumes ou hábitos dentro de uma sociedade por "obra da razão prática coletiva e individual" (MAUSS, 2017, p. 425) com um objetivo ou significado específico. Neste artigo, esses hábitos se referem a todas as técnicas ligadas ao ciclo menstrual. Figuram-se entre esses hábitos: as distintas maneiras de recolhimento do sangue; os chás e outras tecnologias utilizadas desde gerações passadas para mitigar as cólicas menstruais; a reclusão; e as bolsas de água quente.

Já para a análise das entrevistas, utilizamos o conceito maussiano de "homem total", derivado do "fato social total" (cf. MAUSS, 2017). No caso deste artigo, tratamos de "mulheres totais", avaliadas a partir de preceitos biopsicossociais para que tenhamos melhor e mais ampla concepção de sua realidade, suas experiências e suas percepções. Portanto, para diagnosticar a "mulher total", necessitamos levar em conta tanto a condição fisiológica e o momento da fase reprodutiva, por exemplo, quanto a quantidade de estresse, a condição social e os aspectos da cultura em que ela está inserida. 


\section{A mão esquerda, as técnicas corporais e a mulher total}

Hertz (1980) começa por explicitar uma série de oposições sociais e, para ilustrar a ideia, se utiliza da oposição do lado direito e do lado esquerdo do corpo, mais especificamente, da mão direita e da mão esquerda. A partir daí, são demonstradas diversas comparações do poder e da influência de cada lado que, em uma primeira avaliação, se mostram como puramente naturais, mas, ao olhar a fundo, percebe-se que a oposição é cercada e reforçada por significados culturais. Fala-se sobre hierarquias sociais, justificadas pela "natureza" das coisas, que têm o intuito de evitar grandes mudanças e de continuar por fortalecer um dos lados, perpetuando uma assimetria. Para isso, com a falta de uma diferença anatômica significativa, recorre-se a processos de mutilação que, por causa de um desenvolvimento frustrado, causam a dependência da mão esquerda sobre a mão direita.

Mais adiante, Hertz (1980, p. 103) esclarece as formas dessa mutilação que "não é marcada porque afeta a função e não a forma externa". Nesse sentido, o que ocorre é o desprezo. Quando o lado esquerdo é reprimido por anos, ele se torna irrelevante e essa irrelevância a ele atribuída faz com que esse lado do corpo não adquira poder. Assim, com uma mão bem treinada de um lado e uma mão fraca e incapaz de outro, fomenta-se um ideal ao qual toda a sociedade deve se conformar: a desteridade. Na obra, Hertz (1980) discute que, exageradamente, o abismo de valores entre tais lados remete às características de uma instituição social de ordem tanto estética quanto moral e que, para entender isso, devemos voltar às representações coletivas anteriores - às crenças e à religião. Uma das formas utilizadas para criar uma assimetria social entre os gêneros foi caracterizar a menstruação como uma impureza e fragilidade.

Para ilustrar as transformações e continuidades simbólicas da menstruação, recorremos à Barbara Walker (1993) que ressalta como na Bíblia o sangue era visto, ao mesmo tempo, como símbolo primário da força da vida (Levítico 17:11), como flores (Levítico 15:24) e como impureza.

Explica a autora que: 
Ao longo dos séculos, as sociedades dominadas pelos homens fizeram esforços importantes para assemelharem a magia feminina do sangue aos deuses ou figuras de salvadores masculinos [...] À parte do conceito da semelhança da dádiva de sangue de Cristo, a sociedade ocidental desenvolveu outros esforços masculinos para se apoderar do simbolismo feminino do sangue e colocá-lo de alguma forma sob o controle masculino. (WALKER, 1993, p. 305)

Desse modo, a autora conclui que "numerosos tabus menstruais espalhados pelo mundo denotavam uma combinação antiga de medo e receio nas atitudes dos homens em relação ao 'sangue da vida'"' (WALKER, 1993, p. 306). Isso pode ser percebido quando as autoridades cristãs afirmaram a impureza do sangue menstrual e, "no século XIII, o Sínodo de Wurzburg estabeleceu que ninguém devia chegar perto dela" (WALKER, 1993, p. 306); ou então quando, no século XVII, "as mulheres menstruadas ainda eram proibidas de entrar numa igreja" e que as mulheres pós-menopausa eram consideradas bruxas, "porque deixavam de expulsar o sangue da sabedoria, retendo-o nas suas veias para assim se tornarem pessoas mágicas" (WALKER, 1993, p. 306).

A oposição entre sagrado e profano é transferida à oposição entre sociedade masculina ou feminina, as quais seriam separadas por proibições e tabus para que, como proteção, não mudem de essência ou desestabilizem as hierarquias estabelecidas. É nesse sentido que podemos interpretar como um símbolo primeiramente positivo (sangue da vida) torna-se negativo (impuro). Contudo, se uma mulher não mais menstruar nem tiver o estigma de fraqueza, ela é novamente vitimizada por desestabilizar as fronteiras estabelecidas, por ter mudado de essência.

Paralelamente, demonstramos como esse dualismo está presente em parte da sociedade brasileira, ao tomarmos a menstruação como uma forma da mão esquerda. É assim que, ao ser comparada a "sociedade dos homens" à "sociedade das mulheres", "se a assimetria orgânica não existisse, ela seria inventada" (HERTZ, 1980, p. 109), ou seja, de uma forma ou de outra, a sociedade dos homens buscaria uma razão para a inferiorização da mulher. 


\section{Método e sujeitos}

As dez mulheres entrevistadas foram divididas nos grupos etários seguintes: 12 a 15 anos; 18 a 25 anos; 38 a 46 anos; e a partir de 58 anos. Todas elas moravam nas localidades de Zona Norte de São Paulo ou no Plano Piloto de Brasília e se identificavam como classe média. Em alguns casos, eram da mesma família com relações de parentesco diretas.

A comunicação com elas foi obtida por meio de entrevistas semiestruturadas realizadas por chamada de voz e de vídeo na internet, que permitiam que as interlocutoras expusessem suas variadas vivências com o mênstruo, desde aquelas que ainda não haviam passado pela menarca, até as que já estavam na menopausa. Direcionamos nossas questões com o intuito de saber a escolaridade de cada uma delas e se tiveram aulas de educação sexual; a idade em que tiveram a menarca, para quem contaram do acontecimento e o que sentiram; as técnicas corporais (incluso a linguagem) que utilizam durante o período menstrual; se fazem algum tipo de acompanhamento médico; se a menstruação é um assunto de conversa em casa e no círculo de amigas; e a que associam o ciclo. Buscávamos compreender o contexto cultural, o apoio social, os conhecimentos biológicos do corpo feminino, o estresse e a confiança que envolviam cada uma delas. Em suma, a história e a relação particular de cada mulher entrevistada com a menstruação.

Para compreender os pontos de vista dos sujeitos desta pesquisa, utilizamos a análise de conteúdo categorial, uma metodologia de análise de documentos que permite o entendimento de cada narrativa de forma pontual (BARDIN, 1995). Assim, a partir de indicadores qualitativos, conseguimos compreender melhor as percepções presentes nos relatos que coletamos e os interesses, as atitudes, as reações e os conceitos de cada mulher sobre o tema "menstruação". Pela análise de conteúdo categorial de Bardin (1995), é necessário criar uma forma de categorizar os dados verbais presentes na comunicação oral. Então, depois da transcrição e ponderação sobre as falas das entrevistadas, categorizamos os campos que a pesquisa abrange. São eles: 1) transmissão de conhecimentos - técnicas corporais - de geração para geração; 2) recorrência do assunto em ambientes variados; 3) perenização dos estigmas; e 4) peso da mídia social para informar e romper tabus. 


\section{A menstruação e a mão esquerda, um tabu}

\subsection{A menstruação e a desinformação}

De acordo com Hertz (1980), ao considerar que o princípio dos costumes e das crenças geralmente é místico e baseado em emoções religiosas, é necessário analisar a origem das ideias presentes na nossa cultura. É dessa maneira que podemos considerar a origem do tabu para com a menstruação: foi e é no reforço do Cristianismo e, durante séculos, na adoção do sangue menstrual como algo impuro pela sociedade:

Mas a mulher, quando tiver fluxo, e o seu fluxo de sangue estiver na sua carne, estará sete dias na sua separação, e qualquer que a tocar, será imundo até à tarde.

E tudo aquilo sobre o que ela se deitar durante a sua separação, será imundo; e tudo sobre o que se assentar, será imundo.

E qualquer que tocar na sua cama, lavará as suas vestes, e se banhará com água, e será imundo até à tarde.

E qualquer que tocar alguma coisa, sobre o que ela se tiver assentado, lavará as suas vestes, e se banhará com água, e será imundo até à tarde.

Se também tocar alguma coisa que estiver sobre a cama ou sobre aquilo em que ela se assentou, será imundo até à tarde.

E se, com efeito, qualquer homem se deitar com ela, e a sua imundícia estiver sobre ele, imundo será por sete dias; também toda a cama, sobre que se deitar, será imunda. (BÍBLIA, Levítico 15:19-24, 1898)

Nas entrevistas com o público da geração de mulheres mais velhas, aquelas com mais de 58 anos, todas tinham algo em comum: o medo da menstruação. Em um dos relatos, M. (68 anos), que menstruou aos 9 anos de idade, contou: "Quando vi o sangue, tive certeza de que iria morrer". Em seu primeiro contato, na própria menarca, ela não sabia do que aquilo se tratava, o assunto nunca havia sido ensinado na escola e dentro de casa não era nem deveria ser comentado. M. teve uma história muito 
parecida com as das outras interlocutoras de seu grupo - D. (67 anos) disse: "Não se falava disso na escola, em lugar nenhum, na verdade". Como ilustrado na charge de Escarlota (Ilustração 1), o problema da desinformação e o medo diante a menarca era algo muito comum e constante para essas meninas.

As explicações mínimas e bastante rasas ao redor do tema, raramente feitas pelas mães das meninas, vinham sempre cheias de proibições e transformavam o sentimento de medo em raiva, aversão e nojo, já que a única parte substancial garantida para as meninas era a dor física e a vergonha. Por essa perspectiva, $M$. foi ensinada que todo o tormento que ela passava uma vez ao mês era necessário para se ter filhos, mas ela enfrentou dificuldades quando mais velha precisou de assistência médica para engravidar. Quanto a D., que só foi aprender sobre o que era o ciclo menstrual depois de adulta, por meio de um programa de televisão, ela reforça que o acesso à informação para sua geração era altamente defasado e difícil.

Devido à falta de esclarecimento sobre o assunto, o único sentimento possível para essas mulheres ao ver o sangue de seu próprio corpo era o desespero e, junto disso, a vergonha. Na maioria das vezes, não contavam para terceiros a respeito da menstruação por algum tempo e, quando o assunto era abordado, a reação desses terceiros, majoritariamente irmãs mais velhas ou primas, era mecânica. Esse cenário negativo criava mais uma barreira. Por conta da quebra de comunicação clara e instrutiva, esses procedimentos eram algo exclusivo às mulheres que lidavam com a menstruação de forma cotidiana, ou seja, que já haviam passado pela menarca. Assim, a sociedade dos homens não era incentivada a ter consciência da prática e o afastamento da mulher desta sociedade neste período tornava-a mais sozinha e reclusa.

As mulheres entrevistadas denunciam que, enquanto meninas, elas deveriam apenas aprender a controlar o sangue para poderem seguir a vida normalmente sem que ninguém soubesse de sua menstruação. Para isso, foram criados termos múltiplos de caráter pejorativo que buscavam esconder a verdadeira natureza do mênstruo. Entre as expressões usadas pelos sujeitos estavam "estar de chico", "estar incomodada" e "naqueles dias". Consequentemente, esses termos geraram um teor profano e impuro a uma reação 
tão vital do corpo e, concomitantemente, o seu apagamento. Isso pode ser explicado pelo texto de Hertz (1980) em que, por sua impureza e por sua representação coletiva, tenta-se excluir a mão esquerda por meio de mutilações. Dessa forma, faz-se uso da instabilidade dos nomes e do caráter evasivo da mão esquerda, ou da menstruação, nesse caso, sentidos pela comunidade para perpetuar uma proposta de esquecimento e reforçar um tabu.

Em decorrência disso, a mistificação por trás da menstruação se tornava cada vez maior. As mulheres entrevistadas relataram que eram instruídas furtivamente por vizinhas, primas e irmãs mais velhas a certas práticas de cunho popular. Entre essas, estavam as proibições de lavar o cabelo, de encostar nos meninos, de andar descalça, de ingerir certos tipos de alimentos e de ir à igreja enquanto estivessem na menarca, para evitar que houvesse consequências como "o sangue subir à cabeça", exemplo dado por $\mathrm{M}$. Todos esses ritos aumentavam ainda mais o medo dessa geração de mulheres para com o mênstruo e a impedia de entender sobre os processos físicos reais do corpo feminino. Dessa forma, salvo pequenas exceções, por muito tempo elas não sabiam reconhecer os sinais das fases do ciclo menstrual e estressavam-se continuamente por causa disso. Como disse D.: "Eu nunca sabia quando iria menstruar. Era sempre uma surpresa desagradável, eu sentia pânico e nervoso porque era muito doloroso e incômodo".

Contudo, as entrevistadas, receando que suas filhas sentissem o mesmo que elas sentiram, optaram por conversar e orientar suas filhas, mesmo que de forma breve e simplória (por influência da vergonha e do medo por qual passaram). Dessa maneira, almejando principalmente o bem-estar físico de sua primogênita, D. falou sobre a menstruação para suas filhas ainda quando pequenas e M. diz que a primeira coisa que fez foi levar a menina ao médico para que ela pudesse fazer o acompanhamento desde o começo. Segundo Bozon e Heilborn (2006), essa ocasião de diálogo entre mãe e filha sobre educação sexual não é recorrente entre todos os grupos sociais brasileiros. Os autores indicam que, geralmente, a prática se limita àqueles detentores de maior capital cultural e principalmente das regiões Sul e Sudeste do país. 


\title{
4.2 A menstruação e a educação formal
}

Para o segundo grupo, as mulheres entre 38 a 46 anos, a menarca não foi uma surpresa. Essas garotas, além da ajuda de suas mães, tiveram uma educação formal sobre a biologia do corpo feminino e entendiam os princípios reprodutivos acordados dentro da academia. Por esse motivo, o menstruar não era trágico ou assustador, uma vez que elas sabiam do que se tratava. Pelo contrário, a primeira menstruação era motivo de orgulho, significava que elas haviam se tornado "mocinhas", como lembrado por L. (46 anos): "Eu tinha um 'orgulhinho' de estar menstruada, achava feminino e como eu não era muito feminina era uma das poucas coisas que eu sentia minha feminilidade."

Um ideal havia sido criado para com seu corpo, seu mênstruo e suas práticas. O "virar mocinha" era como a marca de um novo status a ser alcançado na sociedade, motivo de ansiedade e, até mesmo, competição entre as garotas. Após a menarca, a menina finalmente deixava a infância de lado para se tornar moça; além de todos os fenômenos fisiológicos envolvidos, a primeira menstruação mostrava o início da capacidade reprodutiva da mulher, o significado mais claro de fertilidade, popularmente. Entretanto, esse imaginário popular coloca a adolescente sob um ponto de vista de objetificação erótica. Com as transformações hormonais, comuns nesta fase, modifica-se também o exterior da mulher em que o crescimento dos seios e o alargamento do quadril, por exemplo, mostram-se presentes.

A transição criança-mulher as faz "femininas" e, a partir de então, sua imagem é sexualizada. Nesse sentido:

\begin{abstract}
[...] pensamos o corpo como um sistema que produz e reproduz significados e é produzido por eles em ações simultâneas e combinadas. [...] Os corpos são o que são produzidos na cultura e não há um corpo natural, mas, um corpo produzido por expectativas de gênero (BRETAS, 2012, p. 254)
\end{abstract}

A educação formal e informal recebida por essas meninas reflete diretamente nas suas expectativas e nas suas práticas acerca de seu próprio corpo e na maneira como ela se coloca em relação a outros corpos. Segundo L.: "Fiquei até de cama de tão forte 
a dor, mas, apesar disso, fiquei feliz porque estava muito ansiosa. Queria virar mocinha, logo".

A menstruação vista com orgulho não seria uma coisa a qual se aceitaria facilmente. Como ocorreu com a imposição da desteridade como predominante e natural, para que o mênstruo fosse perpassado como processo necessário para a feminilidade, ainda que de maneira contida, ele teve de ser mascarado como um ideal e reforçado por sanções positivas (cf. HERTZ, 1980). Dessa forma, à menina que já havia menstruado e agora era uma mulher, foi atribuída uma melhor posição, um melhor status. O teor fortemente reprodutivo afirmado dentro da comunidade das mulheres e dos homens para essa geração é mostrado no artigo de Snow (2007), no qual o autor argumenta que as mulheres brasileiras apresentavam uma aceitação maior frente à menstruação por causa de uma visão mais tradicional acerca da função reprodutiva da mulher. Assim, a vinda mensal do sangue as lembrava de seu papel "inato" para com a reprodução.

Mesmo com essa mudança de concepção sobre o mênstruo, o "estar menstruada" era considerado algo íntimo, que não devia ser comentado abertamente, continuava a se tratar de um assunto delicado:

Eu lembro que a gente escondia o absorvente, dentro da calça ou no bolso. Eu tinha vergonha claro, se alguém visse, de comprar o absorvente na farmácia e tudo, mas eu ficava vaidosa eu sabia que as meninas sabiam que eu estava indo trocar o absorvente, então eu pegava pra guardar meio querendo que alguém visse, pra ver que eu era mocinha. Eu não sei porquê, mas me sentia valorizada por algum motivo (L. 46 anos).

O medo de que a comunidade tomasse consciência do mênstruo continuava presente. As mulheres mantinham a culpa e a vergonha de serem reconhecidas em seu ciclo. Por isso, foram constantes os relatos sobre qual tipo de roupa elas utilizavam para essa época do mês e como elas levavam os absorventes para que ninguém visse. D. (43 anos), ao falar de sua menarca, lembra que chorou pelo receio de que sua mãe contasse para as amigas sobre o ocorrido, já que era recorrente que, para afirmar um papel social, essa "conquista" fosse comunicada dentro do círculo social. Para 
ela, porém, a menstruação era um acontecimento particular que só as pessoas mais próximas, nas quais ela confiava, deveriam saber. Ao mesmo tempo, as mulheres desse grupo estavam concentradas em mitigar o desconforto físico durante o ciclo menstrual, uma vez que já estavam em posse de mais informações sobre esse processo fisiológico. Dessa forma, a busca por contraceptivos orais com o intuito de controlar os sintomas do sangramento foi crescente nas décadas de 1980 e 1990, momento em que elas mesmas estavam à procura de algo para diminuir sua dor e sofrimento (cf. PEDRO, 2003). Esses medicamentos eram de fácil acesso e poderiam ser adquiridos tanto dentro de estabelecimentos comerciais quanto em organizações não governamentais.

\subsection{A menstruação e a educação social}

Para os dois últimos grupos entrevistados, as meninas de 12 a 15 anos e as de 18 a 25 anos, tudo ocorreu de maneira diferente. Notamos que elas tiveram muito mais acesso à informação sobre o ciclo menstrual, uma vez que disso tratavam na escola. A educação formal que essas garotas tiveram abrangia a educação sexual tanto durante o ensino fundamental quanto no ensino médio, ainda que de forma básica. Dessa forma, a maioria das meninas antes de chegar à menarca, em média, de 11 aos 12 anos de idade no Brasil (BARROS et al, 2019), já havia aprendido sobre o processo através de uma personalidade com autoridade e na qual elas confiavam, a professora. Na teoria de Mauss (2017), a professora poderia ser configurada como possível sujeito na transmissão de técnicas do corpo. Assim, elas encararam o assunto como uma necessidade básica comum que devia receber sua devida atenção. Entre as entrevistadas, todas foram ao médico logo após a primeira menstruação.

N. (18 anos) relata que a primeira aula que teve sobre o sistema reprodutor feminino, no $6^{\circ}$ ano do ensino fundamental, foi "engraçada". Mesmo que a maioria dos alunos já soubesse o que era a menstruação, como ela que havia aprendido em casa com os pais, ainda havia acanhamento e vergonha ao falar sobre esse assunto. Quanto às outras vezes, transcorreram com muito mais tranquilidade, uma 
vez que todas as meninas já haviam passado pela menarca e lidavam cotidianamente com o ciclo há algum tempo.

Esse conhecimento sobre o corpo feminino possibilita que cada mulher possa compreender as particularidades de seu corpo e as possibilidades para lidar com os efeitos da menstruação. Nesse sentido, tenta-se aliviar, de alguma forma, o peso da "necessidade" de se estar dentro de um padrão desejado ou esperado. Por essa perspectiva, o surgimento dos métodos alternativos de saúde menstrual aproxima essas mulheres a uma experiência mais confortável. Comparativamente, é perceptível que, tanto nos resultados apresentados por Bertoni et al. (2011), quanto em nossas entrevistas, as garotas de até 25 anos apresentam menos medo e tristeza na menarca e menos vergonha das menstruações do que as mulheres de grupos etários mais elevados.

Entretanto, o desconforto fisiológico e psicológico continua presente. Por isso, foi necessário que as meninas conquistassem maior liberdade e confiança para compartilhar suas experiências em lugares variados. Percebemos que isso só foi possível quando as garotas tinham alguém próximo que as pudesse ajudar, como uma irmã, que as incentivavam a entender o corpo além da biologia; ou em função do tempo, quando, ao alcançarem maior maturidade, percebiam que era mais incômodo manter o tabu do que falar sobre o assunto:

Eu já tive nojo da minha menstruação porque ouvia muita gente dizer que fedia, que era sujo e tal. Mas isso acabou quando eu percebi que o cheiro forte que exala é pelo contato do seu sangue com o absorvente e com o ar também. Além disso, o contato com outras amigas sobre esse assunto abriu bastante minha mente sobre isso e eu entendi que sangue de menstruação é o mais limpo do mundo, até porque uma vida seria gerada a partir dele. (I. 20 anos)

Mesmo com a dor e com os sintomas da tensão pré-menstrual presentes, a vivência da menstruação caminha para uma situação de maior compreensão que ajuda na construção de um relacionamento mais positivo da mulher com o seu corpo. Contudo, ainda que as meninas mais novas, do grupo de 12 a 15 anos, tenham tido o acesso às mesmas informações e a menarca não tenha 
sido algo que as pegou despreparadas, elas ainda sentem vergonha de falar sobre o assunto, preferindo ignorar e só falar sobre quando for estritamente necessário. Como lembra T (12 anos): "Querendo ou não é meio chato você sempre ter que ficar indo no banheiro, se preocupando se manchou ou não a roupa". O processo de naturalização, apropriação, reconhecimento e aceitação da menstruação é diferente para cada menina, já que cada uma apresenta um ciclo e uma vivência particular (AMARAL, 2003).

Ainda são poucos os espaços ocupados principalmente por mulheres em que é possível falar abertamente sobre a menstruação, o que implica que cabe às mulheres mudarem como elas próprias entendem seu processo menstrual e a simbologia atrelada a esse ato. A partir do momento em que entendemos que o mênstruo nos pertence, a mulher é capaz de desenvolver uma espécie de domínio (ou autoria, ou mesmo autoridade) maior sobre seus atos perante o ciclo e, logo, transformar suas percepções e a das pessoas que lhe cercam sobre a menstruação:

Eu já senti vergonha de estar menstruada, tipo, não de estar menstruada, mas no começo eu sempre achava que alguém ia sentir o cheiro ou desconfiar quando eu ia muitas vezes ao banheiro. Aquela vergonha de sacar o absorvente na bolsa no meio da sala de aula que toda garota já sentiu. Hoje em dia eu nem ligo mais, só falto sair na rua gritando: 'Estou menstruada, ok!? Respeite meu espaço. (I, 20 anos).

Nesse sentido, as meninas mais velhas do grupo de 18 a 25 anos lembram a vergonha que tinham, mas, durante as entrevistas, deixam claro que já se sentem mais confortáveis de conversar com as amigas sobre o período menstrual. Um fator observado quanto a isso foi o do papel exercido pelas redes sociais na informação e naturalização das práticas em torno da menstruação. Enquanto uma parte da mídia continua a reforçar uma imagem fantasiosa, por meio de discursos publicitários que refletem a visão do patriarcado sobre a menstruação (suja, impura e que deve ser escondida), as redes sociais vêm transformando e abrindo espaço a novas narrativas sobre o período menstrual. As meninas por nós entrevistadas relatam que encontraram um lugar seguro, ainda 
que cibernético, para que possam conversar sobre suas experiências e, assim, além de adquirir informações, elas encontram outras pessoas com as quais se identificam. Dessa forma, diversas páginas no Instagram trabalham com a curadoria de artes e dados com o intuito de incentivar o debate de questões relacionadas à saúde menstrual, por exemplo a conta@menstru.acao retratada nas Ilustração 2 .

Considerando que todas as entrevistadas tinham acesso às redes sociais, avaliamos as hashtags "menstruação" e "ciclo menstrual" e encontramos diversas páginas no Instagram, no Twitter e no Facebook que abordam o tema de forma séria, leve e natural ao compartilhar dados sobre saúde menstrual organizados e pesquisados por profissionais da área e ao criar conteúdo como desenhos, pinturas e poemas, trazendo um ar mais otimista e, ainda assim, realista para o mênstruo. A possibilidade de contato com a menstruação de forma tão direta, frequente e aberta, através de uma educação ampla faz com que essa geração possa ter um acompanhamento mais próximo de seu ciclo:

O movimento feminista e suas diversas abordagens têm avançado nos últimos anos e, com as plataformas das redes sociais, levanta questionamento de tabus, além de fornecer espaço para debate e desconstrução. Com isso, as mulheres sentem-se mais livres para falar sobre menstruação, alterando a relação com seu próprio corpo e com o papel que exercem na sociedade (RATTI et al, 2015, p. 13).

Um ambiente de conversa seguro em casa, na escola, no consultório médico, nas redes sociais ou entre amigas permite que as mulheres troquem experiências e, potencialmente, percebam que cada corpo tem suas próprias funcionalidades e diferenças, expressas por diversos modos e técnicas corporais, para acompanhar o ciclo menstrual. 


\section{Considerações finais}

Observamos que cada mulher, cada corpo se utiliza de múltiplos métodos de cuidado com a menstruação, particulares, aperfeiçoados ou não, de outros já existentes. Nesse sentido, a partir da imitação prestigiosa, as mulheres de todos os grupos presentes nessa pesquisa aprenderam sobre as técnicas utilizadas durante o ciclo, como o uso de chás para aliviar as dores, a reclusão social e os diversos jeitos de recolher o sangue, ao conversar com mulheres mais velhas. Por essa perspectiva, a transmissão de conhecimentos ocorre, de geração para geração, quando as meninas mais novas entram em contato com outras mulheres, mais velhas ou mais experientes, que as auxiliam ou as informam sobre o ciclo.

Notamos que, dentro do grupo de entrevistadas, a presença e o contato com o assunto do ciclo menstrual dentro do ambiente escolar, ou seja, em um espaço social legítimo, teve um grande impacto no entendimento das meninas sobre a biologia dos seus corpos e, consequentemente, no entendimento de sua realidade. Assim, diversos tabus que excluíam a mulher menstruada da convivência social, formulados em crenças populares, começaram a ser quebrados lentamente. Com a consciência desses novos fatos, as garotas iniciam gradualmente a conquista de sua autonomia, podendo modificar a percepção de seu mênstruo de acordo com suas particularidades.

O contato com essas informações permitiu que as entrevistadas perdessem o medo e, com o passar do tempo, ao conhecer melhor o ciclo, a vergonha. As garotas ganham mais confiança de seus processos e vivências e isso as leva a conversar sobre a menstruação no seu círculo de amigas. A partir disso, juntas, constroem, aos poucos, uma relação mais amigável e saudável com o mênstruo e entre si mesmas. Em suma, isso mostra que, quando algumas mulheres se encontram e é gerada uma identificação entre elas, o peso do tabu pode diminuir e o olhar para a menstruação pode sofrer uma transformação. Entretanto, essa possibilidade depende da abertura à discussão do assunto como condição necessária para superar o tabu.

Em um momento mais recente, percebemos que a presença dos indivíduos que se preocupam em abordar o tema menstruação 
de forma positiva e educativa dentro das redes sociais é de imprescindível influência na reinterpretação da visão da nova geração sobre o mênstruo. Plataformas com o Instagram, o Twitter e o Facebook oferecem mais um campo para a discussão da multiplicidade de vivências. Além disso, adicionamos aqui a preponderância do movimento feminista para com o debate e a desconstrução de estigmas sobre o mênstruo. Esse movimento cresce em diversas esferas da vida da mulher, inclusive nas mídias sociais, e, ainda que impacte poucas pessoas percentualmente, é um dos responsáveis por fomentar discussões sobre os mais variados temas que refletem na realidade das garotas, como a menstruação.

Contudo, entendemos que mesmo que diversos paradigmas sejam desconstruídos diariamente e que novos espaços para discussão sejam criados e conquistados constantemente, a menstruação ainda tem um longo caminho para percorrer até alcançar aceitação na sociedade. Milhares de mulheres no Brasil não detêm condições básicas de saúde menstrual e isso, além de se figurar como uma séria questão de saúde pública, reflete a desigualdade social brasileira e afeta diretamente as concepções e as experiências que essas pessoas desenvolverão com o menstruar. Reafirmamos, portanto, que o estudo da menstruação, em qualquer contexto que seja, deve levar em conta os fatores biopsicossociais dos indivíduos e considerar que cada um carrega uma historicidade própria e cada corpo se comporta de uma maneira singular. Sinalizamos que fatores como a idade, a escolaridade, o contexto demográfico, o entorno social, as expectativas de comportamento e o conhecimento prévio de cada mulher interferem diretamente em sua relação com seus corpos e o mênstruo desde o início, inclusive na forma com que elas transmitirão seus conhecimentos para outras mulheres.

Por fim, este artigo frisa a relevância de projetos, estudos, espaços, situações e pessoas que, se valendo da percepção plural dos corpos, almejam desenvolver uma leitura mais verídica sobre o ciclo menstrual com o intuito de desconstruir tabus e dar a mulher maior possibilidade de escolha. Afinal, as percepções e as práticas do ciclo menstrual de cada mulher em uma mesma sociedade estão ligadas em forma de cadeia. Ou seja, as ações e interpretações de uma tem influência, ínfima ou não, nas ações e interpretações de todas as outras. 


\section{REFERÊNCIAS}

AMARAL, M. C. E. Percepção e significado da menstruação para as mulheres. 2003. Dissertação (Mestrado em Ciências Médicas) - Faculdade de Ciências Médicas, Programa de Pós-Graduação em Ciências Médicas, Universidade Estadual de Campinas, São Paulo, 2003.

BARDIN, L. Análise de conteúdo. Lisboa: Edições 70, 1995.

BARROS, B. S. et al. ERICA: idade da menarca e sua associação com o estado nutricional. Jornal de Pediatria, Porto Alegre, v. 95, n. 1, p. 106 $111,2019$.

BERTONI, N. C. et al. O significado da menstruação para a mulher no início do século XXI. Arquivos Médicos do Hospital e da Faculdade de Ciências Médicas da Santa Casa de São Paulo, São Paulo, v. 56, n. 2, p. $51-56,2011$.

Bíblia, A. T. Levíticos. In: BíbLIA SAGRADA Almeida Revista e Corrigida. Tradução: João Ferreira de Almeida, 1898. Disponível em: https://www. bible.com/pt/bible/212/LEV.15.ARC Acesso em: 11 dez. 2020.

BOUZAS, I. As principais queixas ginecológicas na adolescência. Adolescência \& Saúde, Rio de Janeiro, v. 3, p 37 - 42, 2006.

BOZON, M.; HEILBORN, M. L. Capítulo 5. In: HEILBORN, M. L. et al. $\mathbf{O}$ aprendizado da sexualidade: reprodução e trajetórias sociais de jovens brasileiros. Rio de Janeiro: Garamond; Fiocruz, 2006. p. 1495-1496.

BRETAS, J. R. S. et al. Significado da menarca segundo adolescentes. Acta paulista de enfermagem, São Paulo, v. 25, n. 2, p. 249 - 255, 2012.

COUTINHO, E. Menstruação: a sangria inútil. São Paulo: Gente; 1996.

ESCAROLOTA. Así son nuestras reglas. Espanha: Pollen, 2019.

HENNEGAN, J. et al. Women's and girls' experiences of menstruation in low- and middle-income countries: A systematic review and qualitative metasynthesis. Public Library of Science Medicine, Manchester, v. 16, n. 5 , p. $1-40,2019$.

HERTZ, R. A preeminência da mão direita: um estudo sobre as polaridades religiosas. Revista Religião e Sociedade, Rio de Janeiro, v. 6, p. 99 - 128, 1980.

MARTIN, E. A mulher no corpo: uma análise cultural da reprodução. Rio de Janeiro, Garamond, 2006.

MAUSS, M. Sociologia e Antropologia. São Paulo: Ubu, 2017. 
MOREIRA, V. P. “Pronto, agora já sou moça”: valores, crenças e saberes que envolvem a menstruação. 2013. Dissertação (Mestrado em Ciências Sociais) - Programa de Pós-Graduação em Ciências Sociais, Centro de Humanidades, Universidade Federal de Campina Grande, Paraíba, 2013.

PEDRO, J. M. A experiência com contraceptivos no Brasil: uma questão de geração. Revista Brasileira de História, São Paulo, v. 23, n. 45, p. 239 - 260, 2003.

RATTI, C. R. et al. O Tabu da Menstruação Reforçado pelas Propagandas de Absorvente. In: CONGRESSO BRASILEIRO DE CIÊNCIAS DA COMUNICAÇÃO - INTERCOM, 37, 2015, Rio de Janeiro. Anais... [S.l.]: [S.n.], 2015. Disponível em: http://portalintercom.org.br/anais/nacional2015/ resumos/R10-0436-1.pdf Acesso em: 26 jun. 2020.

SALA, N. C. Menstruación decolonial. Revista Estudos Feministas, Florianópolis, v. 28, n. 1, p. $1-13,2020$.

SARDENBERG, C. De Sangrias, Tabus e Poderes: A Menstruação em uma perspectiva sócio-antropológica. Revista Estudos Feministas, Florianópolis, v. 2, n. 2, p. 314-344, 1994.

SILVA, S. de A. Desvelando a netnografia: um guia teórico e prático. Intercom, Revista Brasileira de Ciência da Comunicação, São Paulo, v. 38, n. 2, p. $339-342,2015$.

SNOW, R. et al. Women's responses to menses and nonbleeding intervals in the USA, Brazil and Germany. Contraception, São Paulo, v. 76, n. 1, p. $23-29,2007$.

WALKER, B. G. Dicionário dos Símbolos e Objectos Sagrados da Mulher. Lisboa: Planeta, 1993. 